\title{
Single Conversion Stage Three Port High Gain Converter for PV Integration with DC Microgrid
}

\author{
Muhammad Arif*, Mohsin Shahzad, Jawad Saleem, Waheed Malik, Abdul Majid \\ Department of Electrical and Computer Engineering, COMSATS University Islamabad, \\ Abbottabad Campus, Pakistan \\ marif@cuiatd.edu.pk
}

\begin{abstract}
A high gain three port converter with a unidirectional port for photovoltaic (PV) side and two bidirectional ports one each for the battery and the DC bus for PV integration to DC microgrid is presented. High gain is achieved by a coupled inductor with switched capacitor, whereas single stage conversion is used between the ports to achieve high efficiency. The proposed converter is modelled in PLECS/MATLAB and the simulated results for various operational modes are validated using a $500 \mathrm{~W}$ prototype. For main operating mode, i.e., single input single output (SISO), the efficiency is calculated to be as high as $96 \%$. Similarly, owing to the reduced number of components, the losses are reduced considerably for different operation modes.
\end{abstract}

Index Terms-Boost; Simulink; Photovoltaic; Hybrid; Buck-boost; Multiport.

\section{INTRODUCTION}

The photovoltaic (PV) power generation increases day by day with global installed capacity of $505 \mathrm{GW}$ at the end of year 2018 [1]. The PV generation system is economical and long lasting solution to remote area electricity generation and distribution system. However, the low generation and intermittent nature of the PV system limit the implementation of this system. Therefore, multiple generation technologies need to be hybridized in order to have a steady availability of the power. For this, the multiport high gain power electronics converter is an obvious solution. Such converters can take input from multiple sources to drive the load.

There are many single or multistage converter topologies as addressed in [2]. The multiport power electronics are highly dense, cost effective, and efficient. In [3], A. K. Bhattacharjee et al. presented a comparison of the different topologies based on multiplier circuit, doubler and transformer.

A special type of multiport converters is a three port converter (TPC) having generating source and storage system. A comprehensive review of TPC topologies is presented in [4]. However, the common issue associated with these topologies is to achieve the high conversion gain suitable for the PV system that always prefers the voltage boosting techniques. M. Forouzesh et al. in [5] have

Manuscript received 22 February, 2020; accepted 4 May, 2020. reviewed the voltage boosting techniques. The techniques presented are the doubler and multiplier circuit, switched capacitor and coupled inductor. The coupled inductor based techniques are preferred for the high voltage and medium frequency applications. Based on these techniques, various high gain three port converters are presented in the literature [6]-[25].

Three port converters are classified as isolated [6]-[11] and non-isolated [12]-[18]. The isolated converter topologies are preferred where galvanic isolation is required, whereas the non-isolated converters are preferred due to the reduced size, cost, and simplicity. The reduced switch three port non-isolated converter topologies further enhance its usability. In [12], a single inductor based non-isolated TPC is presented. The basic buck and boost converter legs are used to process power between ports. Although converter topology is simple, but the gain is low. Also, the use of too many passive components and multistage power conversion reduce the converter efficiency. In [13], F. Kardan et al. proposed a TPC by using the conventional buck-boost converter. Authors developed prototype of $153 \mathrm{~W}$ at switching frequency of $30 \mathrm{kHz}$. The converter topology is simple and has flexible operation. However, the gain of the converter is very low along with too many passive components. In [14], R. Faraji et al. presented a coupled inductor based non-isolated TPC. Authors developed a $150 \mathrm{~W}$ prototype at $50 \mathrm{kHz}$ for $400 \mathrm{~V}$ DC Bus. They used battery port applying the buck converter. Ch.-M. Lai et al. in [15] used a coupled inductor and capacitor stack based converter for fuel cell application. The converter has relatively high gain, but with too many passive components in the topology. An integrated three port converter for PV system is presented in [16]. Authors explain the complete energy management and control strategy of the proposed converter. The converter topology is simple, but has relatively low gain. In [17], B. Honarjoo et al. presented a single coupled inductor-based TPC for the PV applications. The converter has single element common for its operation. Although converter has high gain and reduced number of devices, it has the demerit of a low reliability.

The advantage of the coupled inductor-based topologies is that the required gain is achieved by an appropriate turns ratio leading to the decreased voltage stress. Due to 
increasing the turns ratio of the coupled inductor for achieving higher gain, it bears the disadvantages of higher leakage inductance, increased losses, and higher voltage spikes. Fortunately, these disadvantages can be overcome by proper design of the coupled inductor and using clamp circuit along with appropriate voltage boosting techniques.

In this paper, a three port bidirectional converter using single conversion stage is proposed. The proposed converter is modified form of the topologies presented in [18], [19] with reduced number of active and passive components while improving the operation of the converter and increasing the efficiency. A coupled inductor along with switched capacitor are used to achieve high voltage gain, which will, ultimately, enhance converter applications. The proposed converter is analyzed in continuous conduction mode (CCM). The battery is connected as it can be charged by the leakage inductance energy. The leakage inductance energy can also be used to achieve the zero voltage switching (ZVS). Moreover, the converter theoretical analysis in the single input single output (SISO) mode, double input single output (DISO) mode, and single input double output (SIDO) modes are explained. As obvious from the literature, higher the component count, higher is the loss in the converter. With reduced number of components used in the proposed converter due to single stage conversion, the loss of the converter is expected to be lesser.

After introduction, the remaining paper is organized as follows. The theoretical and operational analysis in different operating modes is elaborated in Section II followed by the detailed design and mathematical modeling of the proposed converter in steady state is discussed in Section III. The Section IV explains the on simulation and hardware results and comparative study. The conclusions and future work are discussed in Section V.

\section{PROPOSED CONVERTER OPERATION}

The proposed converter is shown in Fig. 1.

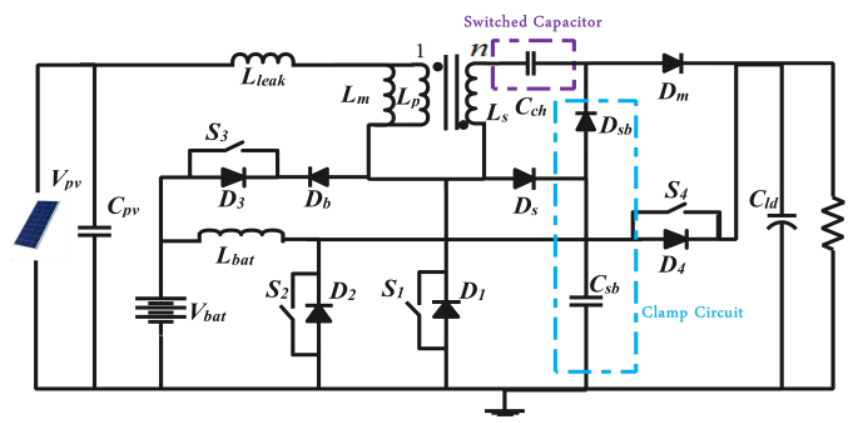

Fig. 1. Proposed converter.

It has three ports: one unidirectional port $V_{p v}$ for $\mathrm{PV}$, one port is $V_{b a t}$ for the battery source, and a bidirectional output port $V_{0}$. A coupled inductor with primary $L_{p}$ and secondary $L_{s}$ winding along with switched capacitor $C_{c h}$ is used to achieve high voltage gain. The proposed converter has bidirectional power flow capability. It has four active switches $S_{1}, S_{2}, S_{3}$, and $S_{4}$, and four diodes $D_{b}, D_{s}$, $D_{s b}$, and $D_{m}$. There are three capacitors: switched capacitor $C_{c h}$, clamp capacitor $C_{s b}$, and the output capacitor $C_{l d}$. The proposed converter operation and analysis are explained for the single input single output (SISO) mode, double input single output (DISO) mode, and single input double output (SIDO) mode. The theoretical switching waveforms are shown in Fig. 2.

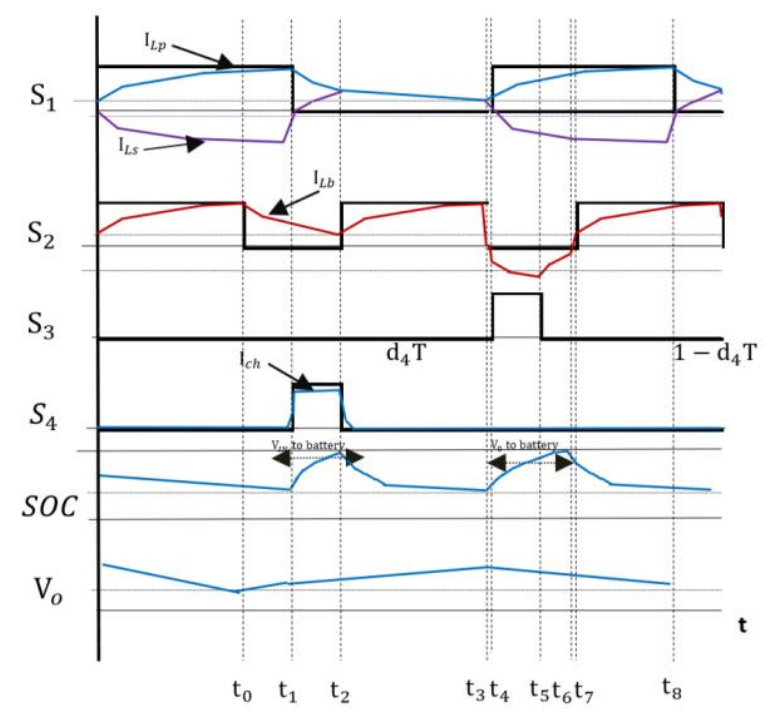

Fig. 2. Theoretical waveforms.

For the operation of the converter, it is assumed that all the components are ideal and capacitors are large enough to maintain the voltage constant.

\section{A. SISO Mode}

Due to a single input and output, only one conversion stage is used in this mode. The proposed converter has following operations.

1. Power transfer from PV to main DC bus (Fig. 3(a))

In this operation, converter supplies power from $\mathrm{PV}$ to the load. The equivalent circuit for this operation is shown in Fig. 3(a). The main operating switch is $S_{1}$. The operation is explained for the following states.

State-1 $\left(0<t<D_{1} T\right)$ : In this state, switch $S_{1}$ is $\mathrm{ON}$ and the current $I_{L P}$ increases. The current $I_{L S}$ decreases, but in opposite direction. The capacitor $C_{s b}$ charges the capacitor $C_{c h}$ through diode $D_{s b}$. The converter has the following equations for this state:

$$
\begin{gathered}
\frac{d I_{L P}}{d t}=\frac{V_{p v}}{L_{p}}, \\
\frac{d I_{L S}}{d t}=\frac{V_{c b}}{n \times L_{p}}, \\
\frac{V_{c l d}}{d t}=-\frac{V_{c l d}}{C_{c l} \times R_{\text {load }}} .
\end{gathered}
$$

State-2 $\left(D_{1} T<t<1-D_{1} T\right)$ : In this interval, coupled inductor energy is transferred to the load. The both currents $I_{L P}$ and $I_{L S}$ are same and decreasing. This interval has the following equations: 


$$
\begin{gathered}
\frac{d I_{L P}}{d t}=\frac{V_{p v}-V_{c l d}}{L_{p}}, \\
\frac{d I_{L S}}{d t}=\frac{V_{p v}-V_{c l d}}{n \times L_{p}} . \\
\frac{V_{c l d}}{d t}=\frac{I_{L P}}{C_{c l}}-\frac{V_{c l d}}{C_{c l} \times R_{l o a d}} .
\end{gathered}
$$

2. Power transfer from battery to main DC bus (Fig. 3(b)) In this operation, the power is delivered to the main DC bus from the battery. As the PV power is not available, load is served by the battery system. The main operating switch is $S_{2}$. The operation is explained for the following time intervals.

State-1 $\left(0<t<D_{2} T\right)$ : In this interval, the switch $S_{1}$ is ON.

The current $I_{l b}$ through the inductor $L_{b a t}$ increases linearly.

This interval has the following equations:

$$
\begin{gathered}
\frac{I_{l b}}{d t}=\frac{V_{b a t}}{L_{b a t}}, \\
\frac{d V_{c l d}}{d t}=-\frac{V_{c l d}}{C_{c l d} \times R_{l o a d}} .
\end{gathered}
$$

State-2 $\left(D_{2} T<t<1-D_{2} T\right)$ : In this interval, the energy absorbed by the inductor $L_{b a t}$ is delivered to the load through the diode $D_{4}$. The following equations govern this interval:

$$
\begin{gathered}
\frac{I_{l b}}{d t}=\frac{V_{b a t}-V_{c l d}}{L_{b a t}}, \\
\frac{d V_{c l d}}{d t}=I_{l b}-\frac{V_{c l d}}{C_{c l d} \times R_{l o a d}} .
\end{gathered}
$$

\section{Battery charging from main DC bus (Fig. $3(c)$ )}

In this SISO mode, the input is main DC link capacitor and the output is battery. The main DC link capacitor is large enough to charge the battery. The main operating switch is $S_{4}$. The operation is explained for the following time intervals.

State-1 $\left(0<t<D_{4} T\right)$ : In this interval, the switch $S_{4}$ is ON and the current through inductor $L_{b a t}$ increases. The equations for this interval are

$$
\frac{d I_{l b}}{d t}=-\frac{V_{c l d}-V_{b a t}}{L_{b a t}} .
$$

State-2 $\left(D_{4} T<t<1-D_{4} T\right)$ : In this interval, the switch $S_{4}$ is off. The inductor $L_{b a t}$ delivers the stored energy to the battery. The equations for these operations are:

$$
\begin{gathered}
\frac{d I_{l b}}{d t}=\frac{V_{b a t}}{L_{b a t}}, \\
\frac{d V_{b a t}}{d t}=-\frac{V_{b a t}}{C_{b a t} \times R_{c h}} .
\end{gathered}
$$

\section{B. DISO Mode: (Fig. 3(d))}

In this mode, PV power is not enough to facilitate the load. The battery is used to compensate for the reduced PV generation. For this mode, the voltage condition is $V_{b a t}>V_{p v}$. So, $D_{2}$ is larger than the duty cycle $D_{1}$.

State-1 $\quad\left(0<t<1-D_{1} T \& 0<t<1-D_{2} T\right)$ : Both the switches $S_{1}$ and $S_{2}$ are $\mathrm{ON}$ and the currents $I_{L P}$ and $I_{L S}$ are increasing. The equations for this interval are:

$$
\begin{gathered}
\frac{I_{l b}}{d t}=\frac{V_{b a t}}{L_{b a t}}, \\
\frac{d V_{c l d}}{d t}=-\frac{V_{c l d}}{C_{c l d} \times R_{l o a d}} .
\end{gathered}
$$

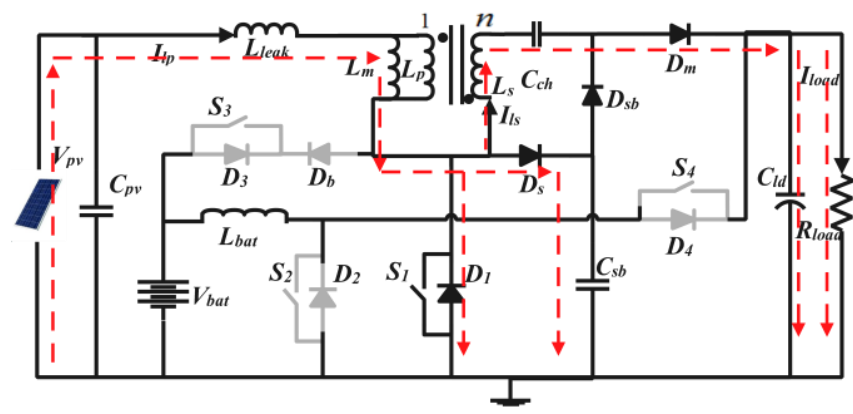

(a)

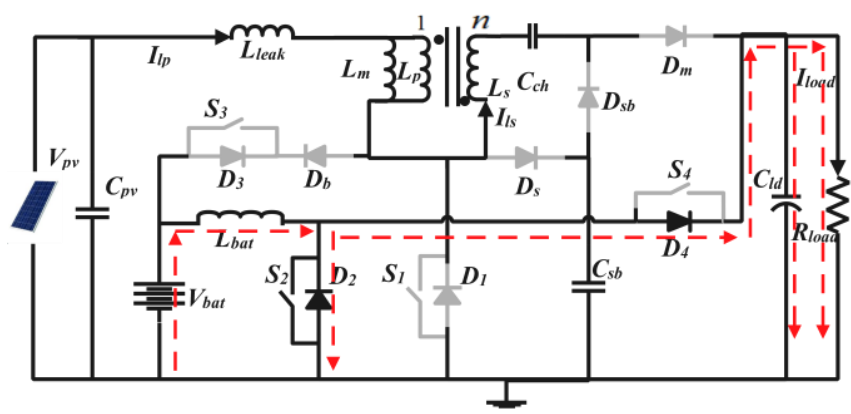

(b)

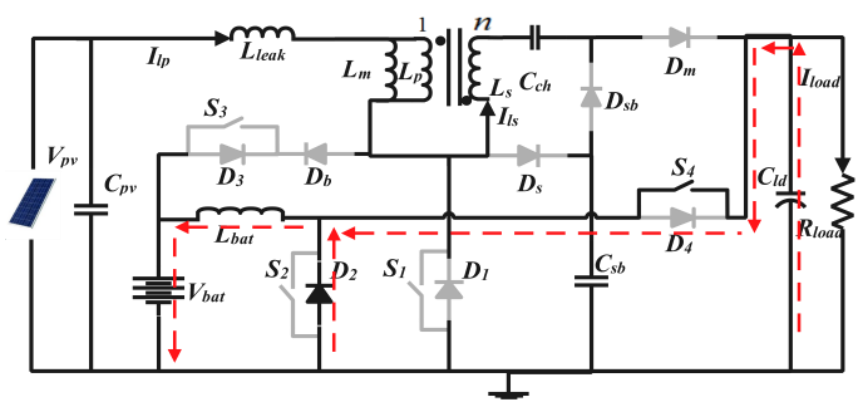

(c)

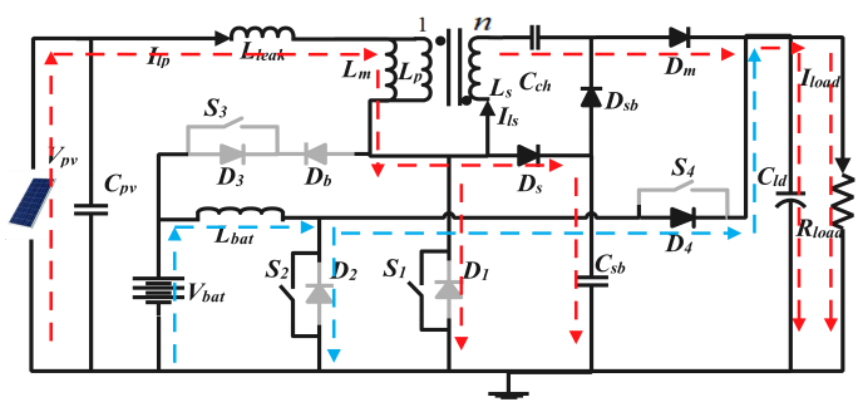

(d) 


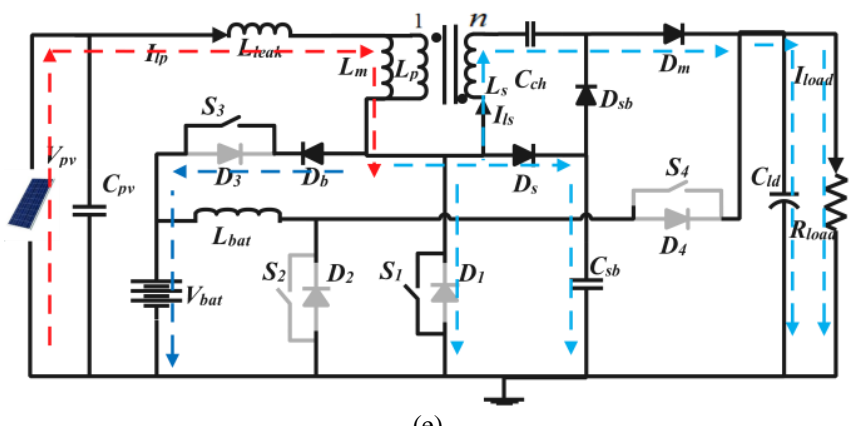

(e)

Fig. 3. Converter configuration: a) PV to main DC bus; b) Battery to main DC bus; c) Main DC bus to battery; d) Both battery and PV to main DC bus; f) (e)? PV to main both battery and main DC bus.

State-2 $\left(D_{1}<t<1-D_{1} T \& 0<t<1-D_{2} T\right)$ : In this interval, the switch $S_{1}$ is off and the switch $S_{2}$ is still on. The equations are:

$$
\begin{gathered}
\frac{d I_{L P}}{d t}=\frac{V_{p v}-V_{c l d}}{L_{p}}, \\
\frac{d I_{L S}}{d t}=\frac{V_{p v}-V_{c l d}}{n \times L_{p}}, \\
\frac{V_{c l d}}{d t}=\frac{I_{L P}}{V_{p v}}-\frac{V_{c l d}}{C_{c l} \times R_{l o a d}} .
\end{gathered}
$$

State-3 $\quad\left(D_{1}<t<1-D_{1} T \& D_{2}<t<1-D_{2} T\right)$ : In this interval, both the switches $S_{1}$ and $S_{2}$ are off. The energy stored in the coupled inductor and $L_{b a t}$ is transferred to the load. The equations for this modes are:

$$
\begin{gathered}
\frac{d I_{L P}}{d t}=\frac{V_{p v}-V_{c l d}}{L_{p}}, \\
\frac{I_{l b}}{d t}=\frac{V_{b a t}-V_{c l d}}{L_{b a t}} .
\end{gathered}
$$

\section{SIDO Mode (Fig. 2(e))}

In this mode, PV generation is in excess and supplies power to both the DC bus and the battery system. The active switches for this modes are $S_{1}$ and $S_{4}$. The state-1 and state-2 of the SISO mode are also valid here for the switch $S_{1}$. The switch $S_{3}$ is used to control the charging current of the battery. For the switch $S_{1}$, the operation of the converter is explained for the following interval.

State-1 $\quad\left(D_{3} T<t<1-D_{3} T \& 0<t<D_{1} T\right)$ : During this interval, the switch $S_{1}$ is on and the switch $S_{3}$ is off. The $L_{P}$ stores the energy and the current $I_{L P}$ increases. This interval is similar to the state- 1 of the SISO mode.

State-2 $\left(0<t<D_{3} T \& t<1-D_{1} T\right)$ : In this interval, the switch $S_{1}$ is off and $S_{3}$ is on. The energy absorbed by the primary inductor $L_{p}$ is used to charge the battery. The following equation explains the operation of the converter in this interval

$$
\frac{I_{l b}}{d t}=\frac{V_{b a t}-V_{c l d}}{L_{b a t}} .
$$

\section{MATHEMATICAL MODELING AND DESIGN CONSIDERATION}

To develop a mathematical model for every mode the averaging of the converter in each mode is performed by applying volt-second balance on inductor currents equations and the ampere-second method on all capacitors voltage equations. The steady state analysis results for each mode are elaborated in SISO, DISO, and SIDO modes.

\section{A. SISO Mode}

\section{Power transfer from $P V$ to main DC bus}

By applying the volt-second balance on the primary inductor $L_{p}$, the voltage across the magnetizing inductor is calculated according to (22), whereas the voltages across the capacitors $C_{1}$ and $C_{2}$ are computed according to (23) and (24), respectively:

$$
\begin{gathered}
V_{L p}=D_{1} \times \frac{V_{p v}}{1-D_{1}}, \\
V_{C_{1}}=\frac{V_{p v}}{1-D_{1}}, \\
V_{C_{2}}=(n+2) \times \frac{V_{p v}}{1-D_{1}} .
\end{gathered}
$$

The steady state voltage across the capacitor $C_{m}$ is computed by using (25) and the output voltage $V_{0}$ across the load is computed by using (26):

$$
\begin{gathered}
V_{c l d}=V_{p v}+V_{l p}+n V_{l p}+V_{C_{2}}, \\
V_{c l d}=\frac{V_{p v} \times\left(2+n+D_{1}(1+n)\right)}{1-D_{1}} .
\end{gathered}
$$

The converter gain increases significantly by increasing the duty cycle and the turn ratio " $n$ " of the coupled inductor The output voltage increases linearly with the input voltage. The proposed converter has the approximate gain of 8 in the SISO mode.

\section{Power transfer from battery to main DC bus}

Applying volt-second balance on the inductor $L_{b a t}$, the voltage across the battery $V_{l b a t}$ and voltage $V_{c l d}$ are given as:

$$
\begin{gathered}
V_{l b a t}=D_{2} \times V_{b a t} / 1-D_{2}, \\
V_{c l d}=V_{b a t} / 1-D_{2} .
\end{gathered}
$$

\section{Battery charging from main DC bus}

The steady state voltage across the battery port is given as

$$
V_{b a t}=D_{4} \times V_{c l d}
$$

\section{B. DISO Mode}

For this mode, applying volt-second balance on the $L_{m}$ 
(magnetizing inductance), the voltage across the magnetizing inductance is computed by using (30)

$$
V_{l m}=\frac{V_{p v} \times\left(D_{1}-D_{2}\right)+V_{b a t} \times D_{2}}{1-D_{1}} .
$$

The voltages $V_{C_{1}}$ and $V_{C_{2}}$ across the capacitors $C_{1}$ and $C_{2}$ are computed by (31) and (34), respectively:

$$
\begin{gathered}
V_{c 1}=\frac{V_{p v}-D_{2} \times V_{p v}+D_{2} \times V_{b a t}}{1-D_{1}}, \\
V_{c 2}=\frac{V_{p v} \times\left[1+n D_{1}-D_{2}(n+2)\right]+V_{c h}}{1-D_{1}},
\end{gathered}
$$

where, $V_{c h}=V_{b a t} \times\left[D_{2}(n+1)+n\left(1-D_{1}\right)\right]$.

The output voltage $V_{0}$ across the capacitor $C_{m}$ is computed by using (33)

$$
V_{0}=V_{\text {pvnew }} \times \frac{V_{p v}\left(D_{1}-D_{2}\right)+V_{b a t} \times D_{2}}{1-D_{1}},
$$

where, $V_{\text {pvnew }}=2\left(V_{p v}+n . V_{b a t}+(2 n+2)\right.$.

\section{SIDO Mode}

In this mode, the only input is from PV. By applying the volt-second balance on the magnetizing inductance $L_{m}$, the

$$
V_{l p}=\frac{V_{p v} \times D_{1}}{1-D_{1}}
$$

The voltage across the capacitors $C_{1}, C_{2}$, and $C_{m}$ is calculated by using (31), (32), and (33), respectively.

The output voltage across the battery $C_{m}$ is calculated by using (35)

$$
V_{b a t}=\frac{\left(V_{p v}\right)}{\left(1-D_{1}\right)} \text {. }
$$

\section{Design Consideration}

The design specifications for the proposed converter are given in Table I. The main elements are the coupled inductor, power metal-oxide-semiconductor field-effect transistor (MOSFETS), capacitors, and diodes. The design of the components, all the relationships of SISO mode are considered. The detailed design of each component is discussed below.

\section{Coupled inductor design}

The coupled inductor is the only magnetic component. The required parameters for the inductor design are shown in Table I. The required values of the coupled inductor are $L_{p}=5 u H$ and $L_{s}=20 u H$ for DCM operation. For the CCM operation, inductor's values are $L_{p}=25 u H$ and secondary inductor $L_{s}=100 \mathrm{uH}$. The Equivalent inductance is $L_{e q}=L_{p}+L_{s}+2 M$, where $M$ is the Mutual inductance. In this work, we use the value of " $n=2$ ". The number of turns for the required inductance value of $L_{p}$ is calculated by using equation (14). The required peak inductor current is $14 \mathrm{~A}$ and the duty cycle $D_{1}=0.49$. For $500 \mathrm{~W}$, core ETD39 and wire AWG-14 are selected. The maximum flux density of the core can be computed by using (36)

$$
B_{\max }=\frac{U_{e f f} \cdot U_{0} \cdot N_{1}^{2} \cdot I_{\max }}{L_{e}} .
$$

The peak current $I_{D p k}$ through diode $D_{3}$ is calculated by using (37)

$$
I_{D p k}=\frac{V_{0}-\left[\left(V_{I N}\right) \times(2+n)-V_{c 2}\right]}{L_{e q} \times\left(1-D_{1} T\right)} .
$$

The peak $I_{L p k}$ primary inductor current is calculated using (38). The peak to peak primary inductor current is $2 \Delta I_{L P}$. The relationship between $I_{L p k}$ and $I_{\text {out }}$ is expressed in $(38)$

$$
I_{L p k}=\frac{I_{\text {out }} \times\left(2+n+D_{1}(1+n)\right)}{\left(1-D_{1}\right)} .
$$

Where N67 material is used and having properties. The parameters are $U_{\text {eff }}=1590, A_{e}=97.1 \mathrm{~mm}^{2}, L_{e}=78.8 \mathrm{~mm}$, and $B_{\max }$ is Maximum flux density. The peak inductor current is defined as:

$$
\begin{gathered}
I_{L p k}=V_{I N} / L_{p} \times D_{1} T, \\
I_{\text {out }}=I_{D p k}\left(1-D_{1}\right)^{2} .
\end{gathered}
$$

The primary inductance value, the loss in the primary inductor, and the magnetizing inductance are calculated by using (41), (42), and (43), respectively:

$$
\begin{gathered}
L_{p}=\frac{V_{\text {IN }}}{(2+n)^{2} \times I_{\text {out }} \times D_{1}\left(1-D_{1}\right) T}, \\
L_{\text {Ploss }}=R_{\text {ESR }} \times\left(\frac{(n+1)}{\left(1-D_{1}\right)} \times I_{\text {out }}\right)^{2}, \\
L_{m}=\frac{n \times D_{1} \times V_{\text {in }}}{f_{s} \times \Delta i_{l p}} .
\end{gathered}
$$

The secondary inductor value is calculated by using the relationship $L_{S}=n^{2} \cdot L_{p}$, where $\mathrm{n}=N_{1} / N_{2}=\sqrt{\left(L_{1} / L_{2}\right)}$ for $N_{1}$ to be the number of turns in the primary and $N_{2}$ to be the number of turns in the secondary. The coupling coefficient between the primary and secondary inductors is calculated by using (44)

$$
k=\frac{M}{\sqrt{L_{p} \times L_{s}}} .
$$

Loss in secondary inductor is calculated by (45) 


$$
L_{\text {Sloss }}=R_{E S R} \times\left(\frac{(n+1)}{\left(1-D_{1}\right)} \times I_{\text {out }}\right)^{2} .
$$

The leakage inductance value in the primary side can be calculated by (46)

$$
L_{l k}=1 /\left(2 . \pi f_{r}\right)^{2} \times C_{o u t s 1},
$$

where $f_{r}$ is the resonance frequency and $C_{\text {outs } 1}$ is the output capacitance of the switch $S_{1}$.

TABLE I. PARAMETERS USED FOR SIMUALTION AND PROTOTYPE.

\begin{tabular}{|c|c|c|}
\hline Parameter's Name & Symbols & Values \\
\hline Input Source-1 & $V_{p v}$ & $48 \mathrm{~V}$ \\
\hline Input Source-2 & $V_{\text {bat }}$ & $96 \mathrm{~V}$ \\
\hline Output Voltage & $V_{0}$ & $380 \mathrm{~V}$ \\
\hline Primary Inductance & $L_{P}$ & $25 \mathrm{uH}$ \\
\hline Secondary Inductance & $L_{S}$ & $100 \mathrm{uH}$ \\
\hline Load Current & $I_{\text {load }}$ & $1.319 \mathrm{~A}$ \\
\hline Load Resistor & $R_{\text {load }}$ & $288 \Omega$ \\
\hline Frequency & $f_{s}$ & $100 \mathrm{kHz}$ \\
\hline Output Power & $P_{0}$ & $500 \mathrm{~W}$ \\
\hline
\end{tabular}

The finite element model of the coupled inductor is developed in Ansys Maxwell. The coupled inductor Ansys analysis report for CCM operation is shown in Table II, where complete details of the coupled inductor performance indicators are discussed in detail. The FEM of the coupled inductor for the magnetic flux density and magnetic flux lines are shown in Fig. 4.

2. Capacitors' selection
Three capacitors used in this topology are i) the clamping capacitor $C_{1}$, ii) the switched capacitor $C_{2}$, and iii) DC link capacitor $C_{m}$. The relationship between the clamp capacitor $C_{m}$ and the input voltage $V_{b a t}$ is expressed in (47)

$$
V_{C_{1}}=\frac{V_{b a t}}{1-D_{1}}
$$

The blocking voltage across the switch $S_{1}$ is expressed in (48)

$$
V_{D S 1}=\frac{V_{b a t}}{1-D_{1}}
$$

The minimum value of the capacitors $C_{1}$ and $C_{2}$ is computed by using equation (48) and (49), respectively:

$$
\begin{gathered}
C_{1 \text { min }}>=\frac{V_{b a t} \times D_{1} \cdot T}{2 \times R_{d s o n 1} \times \Delta V_{C_{1}}}, \\
C_{2 \text { min }}>=\frac{V_{c 1} \times D_{1} \cdot T}{2 \times R_{d s o n 1} \times \Delta V_{C_{2}}} .
\end{gathered}
$$

Similarly, the voltage across the capacitor $C_{2}$ and the value of the output capacitor $C_{m}$ are calculated by using (50) and (51), respectively:

$$
\begin{gathered}
V_{C_{2}}=\frac{V_{I N} \times\left(-1+2 . D_{1}+2+n\right)\left(1+n\left(1-D_{1}\right)\right)}{\left(1-D_{1}\right)}, \\
C_{m}>=\frac{V_{I N} \times D_{1} \times T}{2 \times R_{\text {load }} \times \Delta V_{c m}} .
\end{gathered}
$$

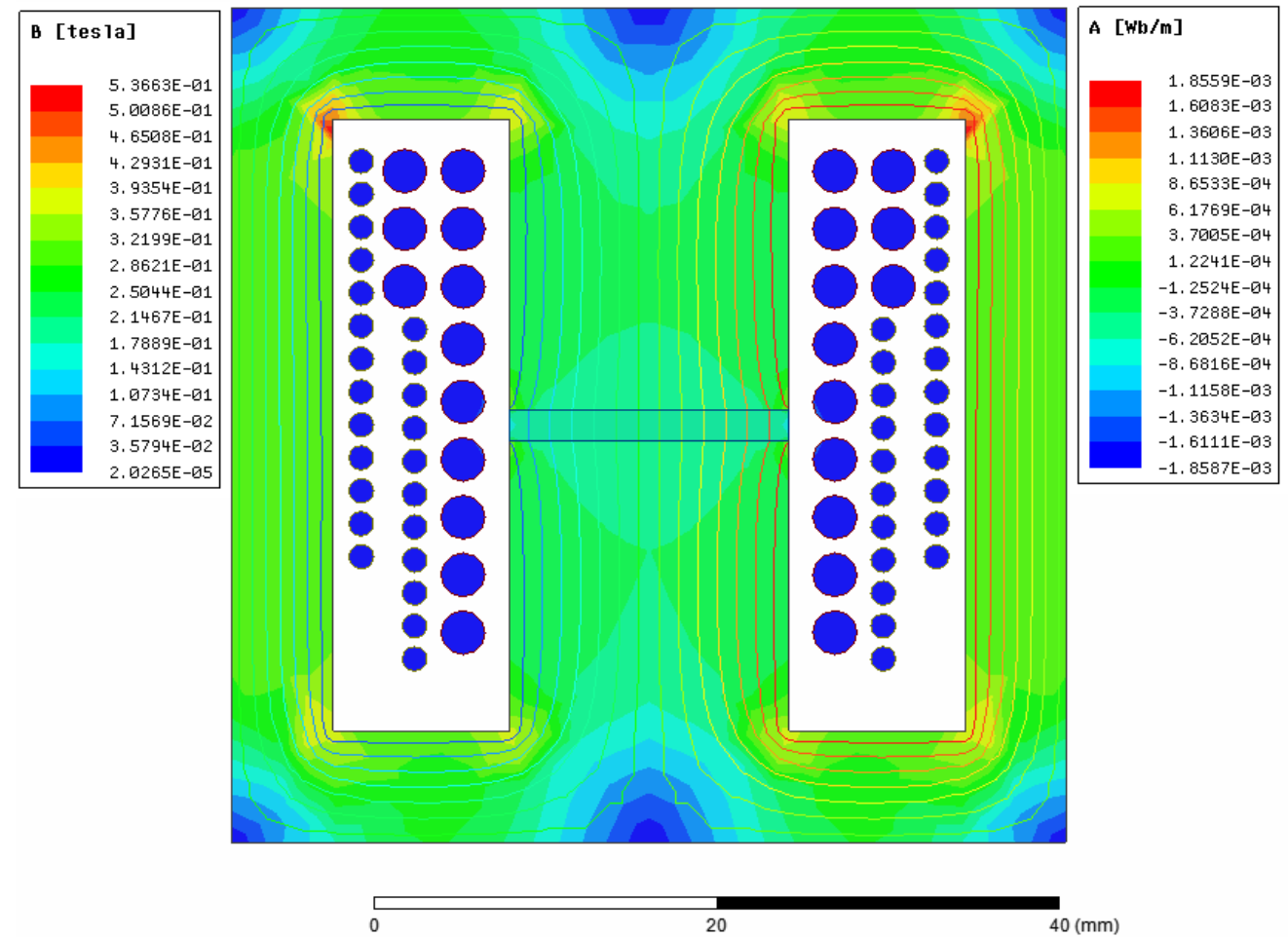

Fig. 4. Magnetic flux line and magnetic flux density (FEA). 
TABLE II. ANSYS MAXWELL ANALYSIS REPORT OF COUPLED INDUCTOR.

\begin{tabular}{|c|c|c|}
\hline & $\begin{array}{c}\text { Primary Inductor } \\
\left(L_{p}\right)\end{array}$ & Secondary Inductor $\left(L_{s}\right)$ \\
\hline $\begin{array}{c}\text { Current } \\
\text { Density }\end{array}$ & $2.88 \mathrm{~A} / \mathrm{mm}^{2}$ & $1.22 \mathrm{~A} / \mathrm{mm}^{2}$ \\
\hline Inductance & $25.00 \mathrm{uH}$ & $100.043 \mathrm{uH}$ \\
\hline Losses & $815.77 \mathrm{~mW}$ & $119.917 \mathrm{~mW}$ \\
\hline$R_{d c}$ & $3.353 \mathrm{~m} \Omega$ & $29.379 \mathrm{~m} \Omega$ \\
\hline \multicolumn{2}{|c|}{ Losses } \\
\hline $\begin{array}{c}\text { Losses } \\
\text { (Winding) }\end{array}$ & $200.684 \mathrm{~mW}$ \\
\hline Losses (Core) & \multicolumn{2}{|c|}{$971.142 \mathrm{~mW}$} \\
\hline Total Losses & Window Occupancy \\
\hline \multicolumn{2}{|c|}{31.09} & 55.72 \\
\hline $\begin{array}{c}\text { Window } \\
\text { Filling (\%) }\end{array}$ & \multicolumn{2}{|c|}{} \\
\hline
\end{tabular}

\section{Switches and diodes}

The switches $S_{1}, S_{2}$, and $S_{4}$ have low blocking voltage capability, while switch $S_{3}$ has high voltage blocking capability. The maximum voltage stress across the main switch $S_{1}$ is calculated by (31). The fast recovery diode is chosen for $D_{c}$, whereas, for $D_{c h}$, ultrafast recovery diode is used. The $D_{p v}$ and $D_{b}$ are the ordinary rectifier diodes with required current and voltage blocking capability. The details of the components rating used for the simulation and prototype are given in the Table I.

\section{RESULTS AND DISCUSSION}

In order to investigate the performance of proposed converter and theoretical analysis, a simulation model of $500 \mathrm{~W}$ converter is developed in PLECS/MATLAB. The proposed converter has high gain in SISO, DISO, and SIDO modes. The complete, simulated, and experimental results for SISO, DISO, and SIDO modes are presented. Main parts of the converter are common to all the ports. The parameters of various components used in simulation model are given in Table I. As the converter has only one coupled inductor, the turns ratio $n$ can be increased by keeping the duty cycle constant in order to increase the gain of the converter. The simulation results and experimental results are explained in the following subsections.

\section{A. Simulation Results}

The PLECS simulation results in SISO mode are shown in in Fig. 5.

The waveforms of control signal $V_{G S 1}$ and the currents $i_{l k}, i_{L S}$, and $I_{L M}$ of the proposed converter in SISO mode are plotted. The duty cycle of $V_{G S 1}$ is $D_{1}=0.49$. The ripples in the magnetizing current are approximately $40 \%$, which can be reduced by increasing the magnetizing inductance value of the coupled inductor. The peak current flowing through the primary inductor $L_{P}$ is $31 \mathrm{~A}$. The current $i_{L S}$ increases with the slope of $V_{C_{1}} / n \times L_{P}$ during the on state of the switch $S_{1}$, while the current $i_{d c 2}$ increases linearly. When the switch $S_{1}$ is off, the current $i_{d c}$ increases abruptly and reaches the value of the $31 \mathrm{~A}$, and then decreases quickly. The ripples in the output voltage $V_{0}$ are approximately $20 \mathrm{mV}$.

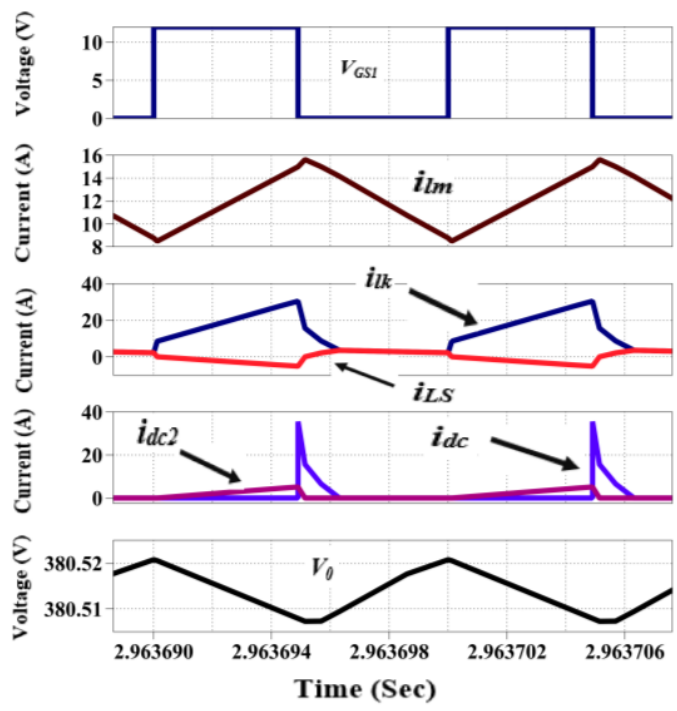

Fig. 5. SISO mode results.

The steady state simulation results for the converter in DISO mode are shown in Fig. 6.

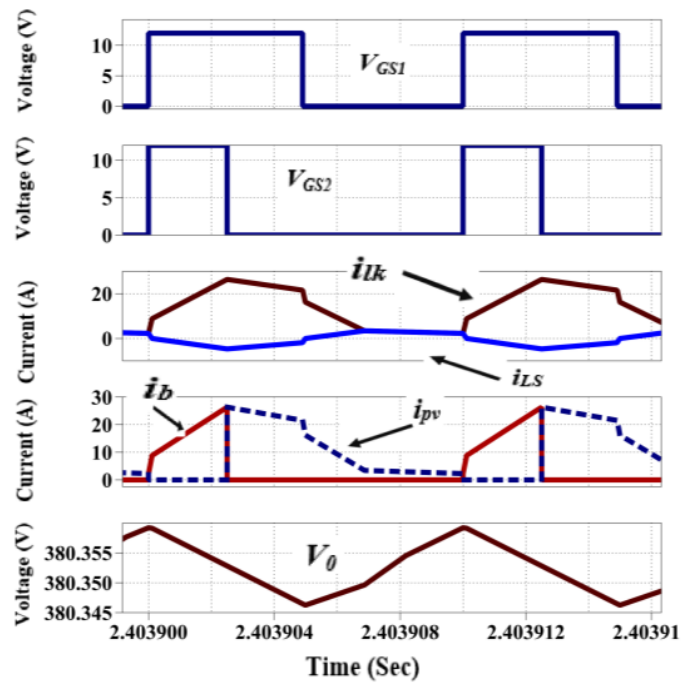

Fig. 6. DISO mode results.

The duty ratio of $V_{G S 1}$ and $V_{G S 2}$ are $D_{1}=0.49$, and $D_{2}=0.25$, respectively. When $S_{1}$ and $S_{2}$ are on, the current $i_{l k}$ increases linearly. During on to off transition of $V_{G S 2}$, the current $i_{b}$ approaches to zero, while the current $i_{p v}$ increases abruptly and follow the current $i_{l k}$. It is observed that the waveforms match the theoretical results of Fig. 2 and inductor current is continuous. In this mode, the current $i_{l k}$ is maintained as current $i_{p v}$ reaches the value of $i_{b}$ as soon as the gate pulse $V_{G S 2}$ disappears. The output voltage $V_{0}$ across the capacitor $C_{m}$ is regulated at $380 \mathrm{~V}$. It can be seen that output voltage ripple is $15 \mathrm{mV}$, which is very little. The simulation results for the SIDO mode of operation are shown in Fig. 7. The results are in close comparison with the theoretical results. The control signal 
$V_{G S 3}$ is used to control the charging current of the battery.

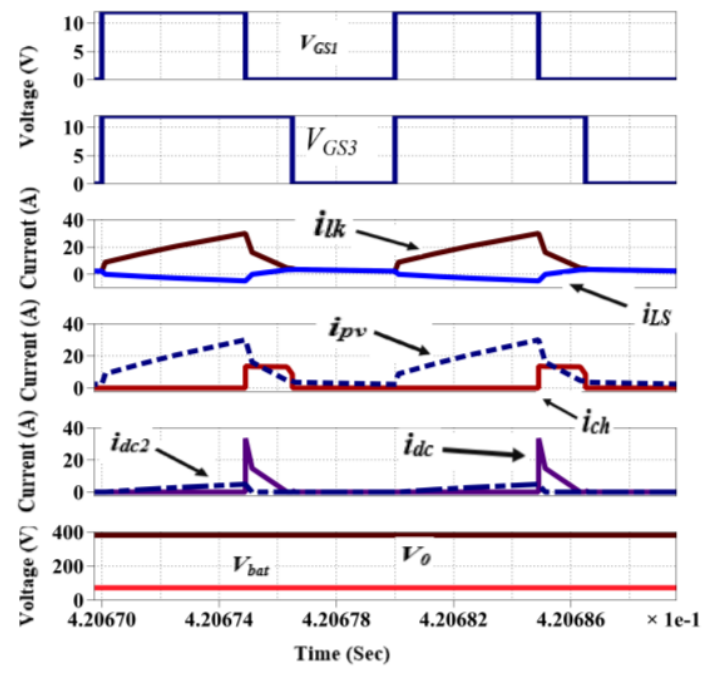

Fig. 7. SIDO Mode Results.

\section{B. Experimental Results}

To validate the theatrical and simulation results, a laboratory prototype is developed and tested. The converter prototype is designed for a power level of $500 \mathrm{~W}$. A photograph of the prototype and laboratory are shown in Fig. 8. The laboratory is equipped with Power supplies, oscilloscope, driving modules, millimeters, and controllers. A four layer printed circuit board (PCB) is developed by using Altium designer with one power plan and one segmented ground plan. In the design of the PCB, the number of controlled interfaces is reduced. This reduces the common mode voltage between the interface ports, so that there is less coupling from the cables into or out of the system. In order to minimize the return current path impedance, the return current path is kept closer to the signal path. "Moats" in PCB ground plan are avoided. All power and ground rails are carefully checked to ensure that they do not offer common impedance routs within or outside the unit. The parameters and specifications of various components used in hardware prototype are given in Table I. For the generation of control signals, TI LaunchpadF28379D is used. The instruments used for measurements are: GDS-810C/Rigol oscilloscope, GDS-2A4S1 driving module, intelliSENS probes, the HOKIE current probes, and multimeter.

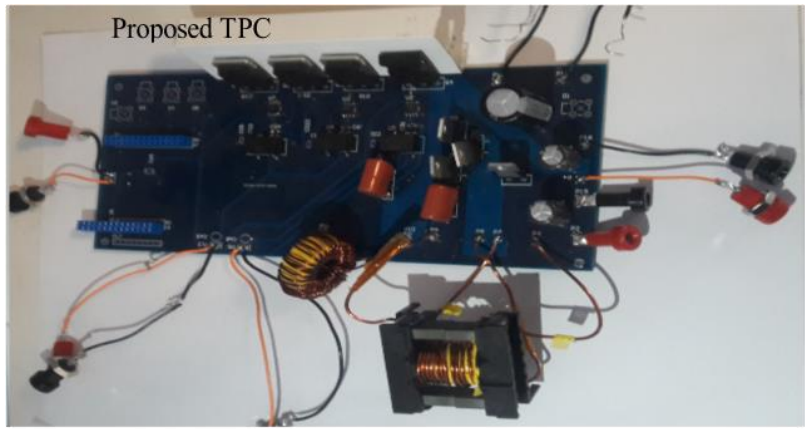

(a)

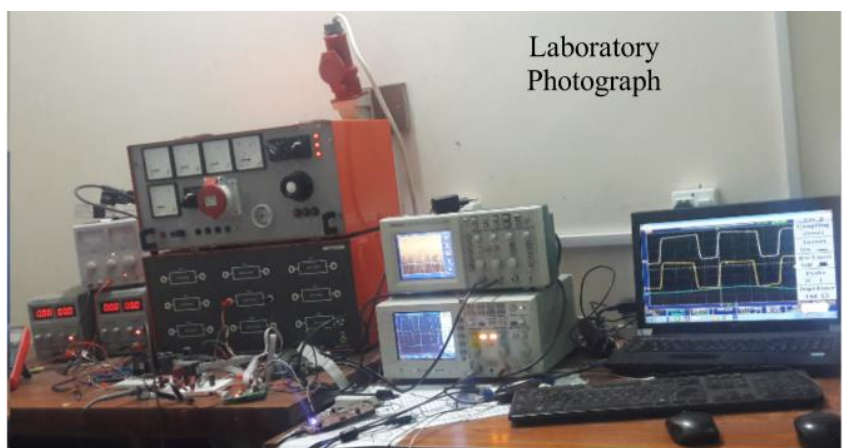

(b)

Fig. 8. Hardware prototype (a) and laboratory photograph (b).

The experimental results for the SISO, DISO, and SIDO modes are shown in Fig. 9, Fig. 10, and Fig. 11, respectively. All the results are in close comparison with the simulation and theoretical results.

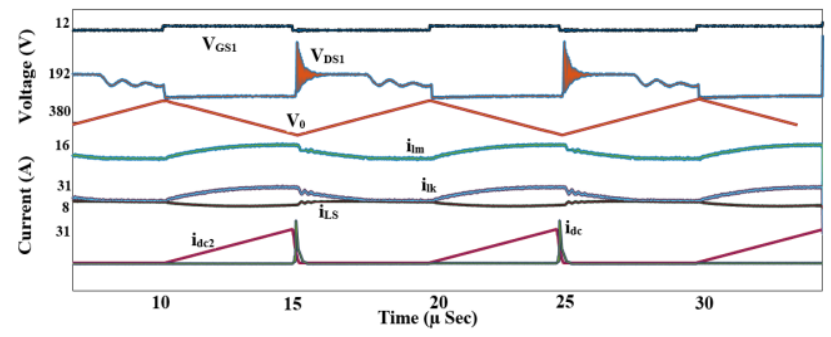

Fig. 9. Experimental Results in SISO Mode.

In Fig. 9, the control signal $V_{G S 1}$ and the block voltage $V_{d s 1}$ of the switch $S_{1}$ are shown. The ripples in the blocking voltage are due to the leakage inductance of the coupled inductor. The currents $I_{d c 2}$ and $I_{d c}$ flowing through the diodes $D_{s b}$ and $D_{s}$, respectively, has smooth transition. The diode $D_{s}$ is Schottky diode and always conduct when the voltage across the switch exceeded the $2 V_{I N}$. The experimental results for the DISO mode are shown in Fig. 10.

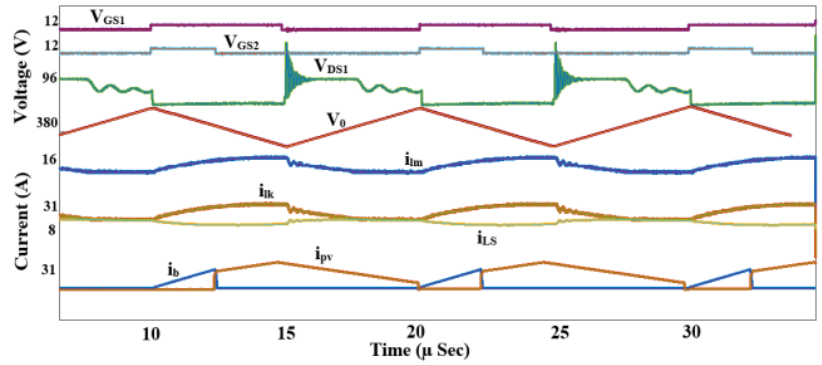

Fig. 10. Experimental Results in DISO Mode.

The control signals are $V_{G S 1}$ and $V_{G S 2}$. In this, the both legs of the converter work indecently keeping the output voltage $V_{0}$ at the desired voltage. Figure 11 shows the SIDO mode results of the converter. The control signals $V_{G S 1}$ and $V_{G S 3}$ along with other currents and voltage waveforms are shown. The proposed converter has almost achieved zero voltage switching (ZVS) in SISO mode. 


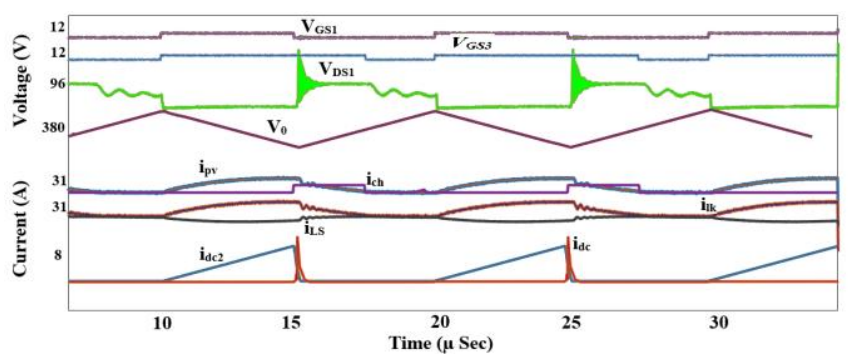

Fig. 11. Experimental results in SIDO mode.

The switch $S_{1}$ is main operating switch in this mode, switch $S_{1}$ is operated under the zero voltage condition without using the extra components. The leakage inductance of the coupled inductor is used to achieve (ZVS). Figure 12 shows $V_{G S 1}$ and $V_{D S 1}$ of the switch $S_{1}$. The Voltage $V_{D S 1}$ is zero before the turning on of gate signal $V_{G S 1}$.

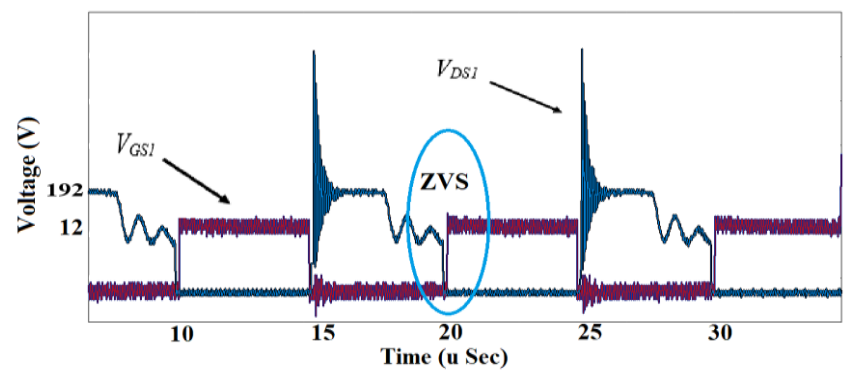

Fig. 12. ZVS condition in SISO mode.

\section{Comparative Study}

The comparison of the proposed converter in terms of the device count and gain is presented in Table III. The proposed converter is compared with the conventional boost converter, with [13] and [17]. In terms of the overall device count, the conventional boos converter has minimum device count but the gain is much less than the proposed converter. Hence, the proposed converter outperforms its counter parts in overall device count and conversion gain. Figure 13 shows the gain comparison of the proposed converter with the [13], [17], and conventional boost converter.

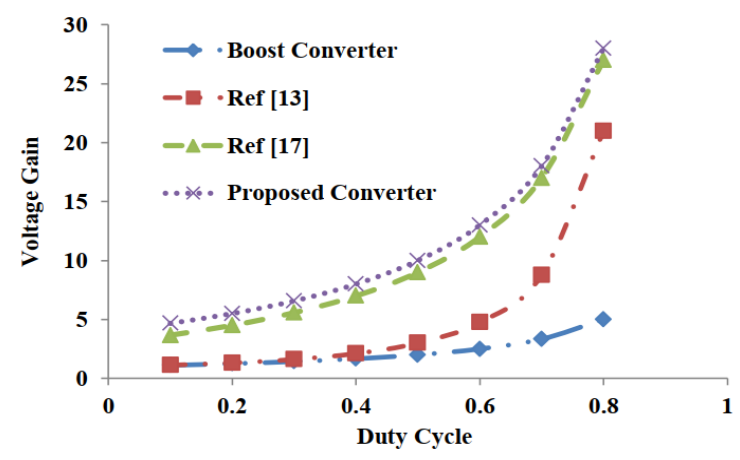

Fig. 13. Voltage gain comparison of the converter in SISO mode.

TABLE III. COMPARISON OF THE PROPOSED CONVERTER.

\begin{tabular}{|c|c|c|c|c|}
\hline Converter & Boost & $\begin{array}{c}\text { Ref. } \\
{[\mathbf{1 3}]}\end{array}$ & Ref. [17] & Proposed \\
\hline Switches & 1 & 4 & 4 & 4 \\
\hline Diodes & 1 & 4 & 4 & 4 \\
\hline Capacitors & - & 1 & 8 & 3 \\
\hline Inductors & 1 & 2 & 1 & 2 \\
\hline $\begin{array}{c}\text { SISO Voltage } \\
\text { Gain }\end{array}$ & $\frac{1}{1-d}$ & $\frac{1+d^{2}-d}{(1-d)^{2}}$ & $\frac{((n+1)+n d)}{1-d}$ & $\frac{\left(2+n+d_{1}(1+n)\right)}{1-d_{1}}$ \\
\hline
\end{tabular}

\section{CONCLUSIONS}

A three port bidirectional power converter using a coupled inductor and a switched capacitor is proposed. The converter has single conversion stage for each source. The minimum number of the common components makes the converter operation more flexible and simple. This leads to the advantage of less prone to the faults with increased reliability. The higher voltage gain is achieved by using active clamp and switch capacitor technique. The operation of the converter is explained in three different modes, i.e., SISO, DISO, and SIDO. Converter efficiency is calculated and loss analysis is performed using analytic, simulated, and experimental models. The proposed converter has $96 \%$ efficiency in SISO mode. A prototype of $500 \mathrm{~W}$ is developed to by using $48 \mathrm{~V}$ and $96 \mathrm{~V}$ inputs and $380 \mathrm{~V}$ output voltage. The measured results of the converter are in closed comparison with simulation results.

\section{REFERENCES}

[1] H. E. Murdock et al., "Renewables 2019: Global status report", 2019.

[2] A. Amir, A. Amir, H. S. Che, A. Elkhateb, and N. A. Rahim, "Comparative analysis of high voltage gain DC-DC converter topologies for photovoltaic systems", Renewable Energy, vol. 136, pp. 1147-1163, 2019. DOI: 10.1016/j.renene.2018.09.089.

[3] A. K. Bhattacharjee, N. Kutkut, and I. Batarseh, "Review of multiport converters for solar and energy storage integration", IEEE Transactions on Power Electronics, vol. 34, no. 2, pp. 1431-1445, Feb. 2019. DOI: 10.1109/TPEL.2018.2830788.

[4] N. Zhang, D. Sutanto, and K. M. Muttaqi, "A review of topologies of three-port DC-DC converters for the integration of renewable energy and energy storage system", Renewable and Sustainable Energy Reviews, vol. 56, pp. 388-401, 2016. DOI 10.1016/j.rser.2015.11.079.

[5] M. Forouzesh, Y. P. Siwakoti, S. A. Gorji, F. Blaabjerg, and B. Lehman, "Step-up DC-DC converters: A comprehensive review of voltage-boosting techniques, topologies, and applications", IEEE Transactions on Power Electronics, vol. 32, no. 12, pp. 9143-9178, Dec. 2017. DOI: 10.1109/TPEL.2017.2652318.

[6] R. N. M. de Oliveira, L. C. dos Santos Mazza, H. M. de Oliveira Filho, and D. de S. Oliveira, "A three-port isolated three-phase current-fed DC-DC converter feasible to PV and storage energy system connection on a DC distribution grid", IEEE Transactions on Industry Applications, vol. 55, no. 5, pp. 4910-4919, Sept.-Oct. 2019. DOI: 10.1109/TIA.2019.2921519.

[7] S. S. Dobakhshari, S. H. Fathi, and J. Milimonfared, "A new softswitched three-port DC/DC converter with high voltage gain and reduced number of semiconductors for hybrid energy applications", IEEE Transactions on Power Electronics, vol. 35, no. 4, pp. 3590 3600, Apr. 2020. DOI: 10.1109/TPEL.2019.2933182.

[8] Y. Wu and I. Chen, "Novel integrated three-port bidirectional DC/DC converter for energy storage system", IEEE Access, vol. 7, pp. 104601-104612, 2019. DOI: 10.1109/ACCESS.2019.2931591.

[9] M. C. Mira, Z. Zhang, A. Knott, and M. A. E. Andersen, "Analysis, design, modeling, and control of an interleaved-boost full-bridge three-port converter for hybrid renewable energy systems", IEEE Transactions on Power Electronics, vol. 32, no. 2, pp. 1138-1155, Feb. 2017. DOI: 10.1109/TPEL.2016.2549015.

[10] Y. Hu, W. Xiao, W. Cao, B. Ji, and D. J. Morrow, "Three-port DCDC converter for stand-alone photovoltaic systems", IEEE Transactions on Power Electronics, vol. 30, no. 6, pp. 3068-3076, Jun. 2015. DOI: 10.1109/TPEL.2014.2331343.

[11] D. Debnath and K. Chatterjee, "Two-stage solar photovoltaic-based stand-alone scheme having battery as energy storage element for rural deployment", IEEE Transactions on Industrial Electronics, vol. 62 no. 7, pp. 4148-4157, Jul. 2015. DOI: 10.1109/TIE.2014.2379584.

[12] T. Cheng, D. D. Lu, and L. Qin, "Non-isolated single-inductor DC/DC converter with fully reconfigurable structure for renewable energy applications", IEEE Transactions on Circuits and Systems II: Express Briefs, vol. 65, no. 3, pp. 351-355, Mar. 2018. DOI: 10.1109/TCSII.2017.2712286.

[13] F. Kardan, R. Alizadeh, and M. R. Banaei, "A new three input 
DC/DC converter for hybrid PV/FC/battery applications", IEEE Journal of Emerging and Selected Topics in Power Electronics, vol. 5, no. 4, pp. 1771-1778, Dec. 2017. DOI: 10.1109/ JESTPE.2017.2731816.

[14] R. Faraji and H. Farzanehfard, "Soft-switched nonisolated high stepup three-port DC-DC converter for hybrid energy systems", IEEE Transactions on Power Electronics, vol. 33, no. 12, pp. 1010110111, Dec. 2018. DOI: 10.1109/TPEL.2018.2791840.

[15] Ch.-M. Lai and M.-J. Yang, "A high-gain three-port power converter with fuel cell, battery sources and stacked output for hybrid electric vehicles and DC-microgrids", Energies, vol. 9, no. 3, p. 180, 2016. DOI: 10.3390/en9030180.

[16] J. Hong, J. Yin, Y. Liu, J. Peng, and H. Jiang, "Energy management and control strategy of photovoltaic/battery hybrid distributed power generation systems with an integrated three-port power converter",
IEEE Access, vol. 7, pp. 82838-82847, 2019. DOI 10.1109/ACCESS.2019.2923458.

[17] B. Honarjoo, S. M. Madani, M. Niroomand, and E. Adib, "Nonisolated high step-up three-port converter with single magnetic element for photovoltaic systems", IET Power Electron., vol. 11, no. 13, pp. 2151-2160, 2018. DOI: 10.1049/iet-pel.2017.0934.

[18] M. Arif et al., "A novel high gain bidirectional multiport DC-DC converter to interface PV, battery, and ultracapacitor with microgrid system", in Proc. of 2017 International Conference on Frontiers of Information Technology (FIT), Islamabad, 2017, pp. 121-126. DOI: 10.1109/FIT.2017.00029.

[19] M. Arif, J. Saleem, Q. Abbas, I. Todorovic, and A. Majid, "High gain bidirectional multiport DC to DC converter for DC microgrid", in Proc. of 2017 International Symposium on Power Electronics (Ee), Novi Sad, 2017, pp. 1-6. DOI: 10.1109/PEE.2017.8171667. 